BMJ Open

Diabetes

Research

\& Care

\title{
Integrative health coaching: a behavior skills approach that improves HbA1c and pharmacy claims-derived medication adherence
}

\author{
Ruth Q Wolever, ${ }^{1,2}$ Mark H Dreusicke ${ }^{2}$
}

To cite: Wolever $R Q$, Dreusicke MH. Integrative health coaching: a behavior skills approach that improves $\mathrm{HbA1c}$ and pharmacy claimsderived medication adherence. BMJ Open Diabetes Research and Care 2016:4:e000201. doi:10.1136/bmjdrc-2016000201

Received 27 January 2016 Revised 23 March 2016 Accepted 29 March 2016

CrossMark

\begin{abstract}
${ }^{1}$ Department of Physical Medicine and Rehabilitation, Osher Center for Integrative Medicine, Vanderbilt Schools of Medicine \& Nursing, Nashville, Tennessee, USA ${ }^{2}$ Duke Integrative Medicine, Duke University School of Medicine, Durham, North Carolina, USA
\end{abstract}

Correspondence to Dr Ruth Q Wolever; ruth.wolever@vanderbilt.edu

\section{ABSTRACT}

Objective: Medication adherence requires underlying behavior skills and a supporting mindset that may not be addressed with education or reminders. Founded in the study of internal motivation and health psychology, integrative health coaching $(\mathrm{IHC})$ helps patients gain insight into their behaviors and make long-term, sustainable lifestyle changes. The purpose of the study is to determine whether IHC improves oral medication adherence, glycated hemoglobin (HbA1c), and psychosocial measures, and to assess whether adherence changes are sustained after the intervention. Methods: Using a prospective observational design, participants $(n=56)$ received 14 coaching calls by telephone over 6 months. Medication possession ratio (MPR) was calculated for time intervals before, during, and after the intervention. $\mathrm{HbA1c}$ and patient-reported psychosocial outcomes were obtained to test interactions with MPR.

Results: Medication adherence (MPR) increased from $0.74 \pm 0.197$ to $0.85 \pm 0.155$ during coaching, and was sustained at $0.82 \pm 0.175$ during a 6 -month period after the study. Better adherence correlated with a greater decrease in $\mathrm{HbA1c}$. HbA1c decreased from $8.0 \pm 1.92 \%$ to $7.7 \pm 1.70 \%$ over the 6 -month intervention. All psychosocial measures showed significant improvement. In addition to discussing medication adherence strategies with their coach, patients discussed nutrition and exercise ( $86.9 \%$ of calls), stress management $(39.8 \%)$, and social support and relationships (15.4\%).

Conclusions: IHC targets internal motivation and supports behavior change by facilitating patients' insight into their own behaviors, and it uses this insight to foster self-efficacy. This approach may yield sustainable results for medication adherence and warrants further exploration for health-related behavior change.

\section{INTRODUCTION}

Diabetes treatment plans involve many aspects that challenge adherence: it is a chronic disease, lifestyle changes are required, and environmental and social factors are important, yet difficult to control.

\section{Key messages}

- Sustained medication adherence requires individualized behavior change strategies and cultivation of motivation that are not addressed with education and reminders.

- Integrative health coaching supports patients to make behavior changes wherever they chooseincluding lifestyle, stress reduction and relationships-and yields improvements in pharmacy claims-derived measures of medication adherence as well as clinical outcomes like glycated hemoglobin.

- Individualized interventions that target internal motivation using patients' own values lead to behavior changes that appear sustainable.

Medication adherence is a well-documented problem, with a systematic review finding adherence rates to oral diabetes medications as low as $36 \% .^{1}$ Non-adherence is associated with worse clinical outcomes and increased risk factors, ${ }^{2}$ increased hospitalization and healthcare service utilization, ${ }^{3-5}$ and elevated healthcare costs. ${ }^{6} 7$

Interventions to increase medication adherence range from simple (automated telephone reminders or text messages) to complex (individualized approaches targeting motivation and psychosocial support). Although simple interventions have shown success with short-term medication regimens, such as a course of antibiotics ${ }^{8}$ or first prescription fills, ${ }^{9-11}$ there is consensus that long-term adherence in chronic illness requires more elaborate interventions. ${ }^{12-14}$

Healthcare professionals may agree that behavior change requires time, effort, and personalized strategies, yet there is debate on the best ways to modify medication adherence behavior. Patient education has historically been a first-line strategy to improve adherence. ${ }^{15}$ However, mounting evidence makes it clear that knowledge alone does not lead to improved self-management 
behaviors. ${ }^{16-18}$ One study even showed a negative relationship between diabetes knowledge and adherence, which suggests that patients who know less about diabetes may be more likely to take their medicine. ${ }^{19}$ To add to this confusion, both patients and caregivers, when asked what would help improve adherence, report that they want education. ${ }^{20}$ This only highlights an important distinction, however, between what patients report they want, and what empirically works.

Lifestyle behavior skills have been shown to be important predictors for medication adherence. One study tested an information-motivation-behavior skills model ${ }^{16}$ and found that both adherence information and motivation were mediated by behavior skills. Examples of behavior skills included skills about how to incorporate a regimen into daily life, adjust medication based on circumstances, acquire support, and self-reinforce over time. Neither information nor motivation alone was enough to impact adherence. Interestingly, this suggests that even highly motivated patients may not be adherent if they lack fundamental behavior skills. While the literature is clear on the importance of patients learning personalized strategies that are applicable in a variety of contexts, $^{21} 22$ structured interventions are needed to promote these strategies.

Health coaching has emerged as a promising intervention to target behavior change. In health coaching, individuals are empowered to achieve self-determined goals through a deliberate and individually tailored learning process. Coaches have a wide knowledge base of health issues and distinct healthcare resources, but their area of expertise is not medicine; their expertise is specifically in helping clients build motivation and personalize strategies for behavior change. ${ }^{23}$ Importantly, and distinct from other approaches, health coaches are trained to engage patients through the entire process of a behavior change, rather than only at the beginning when making a plan and at the end when reporting on the plan.

The type of coaching used in the current study-integrative health coaching (IHC) - addresses health behavior changes by having patients envision how they want their life to look overall: from the perspective of their physical health, emotional well-being, social connections, personal and career development, and even spirituality. ${ }^{23-25}$ To move toward a personal vision of health, patients determine their own goals, and coaches address the patients' core values and sense of purpose to cultivate motivation. In IHC, specific goal attainment is a secondary outcome, while the primary objective is learning how to change one's behavior in a sustainable fashion. ${ }^{26}$ Paradoxically, this approach often yields the results which would be desired from a conventional medical paradigm. Studies of IHC have demonstrated lower risk for cardiovascular disease, ${ }^{27}$ diabetes and stroke, ${ }^{28}$ improved weight control, ${ }^{26}{ }^{29-31}$ better management of intractable tinnitus, ${ }^{32}$ and improvements in diabetesrelated psychosocial measures. ${ }^{33}$
The purpose of the present study was to determine whether IHC facilitates and sustains pharmacy claimsderived oral medication adherence, glycated hemoglobin (HbAlc), and psychosocial measures. We hypothesized that 6 months of pharmacy claims data would demonstrate improvement when compared with the previous year of precoaching claims data in terms of patients' medication possession ratio (MPR). We further hypothesized that adherence would be sustained after coaching ended, with no change in MPR between the coaching period and a 6-month postcoaching period. Finally, we hypothesized that improved adherence would correlate with a decrease in HbAlc.

\section{RESEARCH DESIGN AND METHODS \\ Recruitment criteria}

Participants were recruited from community postings and prior study pools. ${ }^{34}$ Inclusion criteria included English speaking, at least 18 years of age, and a diagnosis of type 2 diabetes treated with oral medications for at least 1 year. Participants may or may not have been taking insulin in addition to their oral medications. All participants provided informed consent, including the use of their pharmacy claims data, and the study was approved by the Institutional Review Board of Duke University Health System.

\section{Study design and procedure}

This study is phase II of another trial. ${ }^{33}$ Phase I was a randomized controlled trial, where one cohort $(n=30)$ received the 6-month IHC intervention, and the other cohort $(n=26)$ was assigned to a usual care wait-list for 6 months. For phase II, the latter cohort received the intervention, and data from both cohorts were combined for the current study $(n=56)$. To allow for adequate power to analyze the claims data, the current study utilized a prospective observational design where each participant served as his/her own control across three time points: precoaching, coaching, and postcoaching.

Participants came to the medical clinic for precoaching and postcoaching assessment visits within 2 weeks prior to their first coaching call, and within 2 weeks following their last coaching call. At both visits, participants completed psychosocial questionnaires, had blood drawn, and HbAlc analyzed by blinded personnel. Between these visits, participants received the IHC intervention.

\section{Intervention}

Participants $(n=56)$ received up to 14 coaching sessions over 6 months. Sessions averaged $30 \mathrm{~min}$ and were provided via telephone at mutually agreed on times. The content and principles of IHC have been described in detail elsewhere. ${ }^{23} 242635$ Participants were encouraged to choose personal goals that were most meaningful to them. The study protocol also required that coaches inquire about barriers to medication adherence at each 
call. Two coaches provided the intervention, and participants were paired with the same coach throughout the study. Both health coaches had completed over $100 \mathrm{~h}$ of training in IHC, and had masters-level degrees in social work or psychology. Coaches also had over $100 \mathrm{~h}$ experience of individualized coaching with patients with type 2 diabetes and had previously facilitated diabetes coaching groups. While there was no national certification at the time of the study, both coaches would have qualified to sit for the newly established national certification examination for health and wellness coaches. ${ }^{36}$

\section{Outcome measures}

Primary outcomes

Medication adherence and HbAlc were the primary outcome measures. MPR was calculated from pharmacy claims data to assess adherence. Oral diabetes medications were filtered using the Uniform System of Classification (USC) level 2 category: diabetes, noninsulin. For each participant, MPR was calculated for three time intervals: the year prior to coaching (pre), the 6-month intervention (coaching), and the 6 months after coaching (post). Data collection for MPR was objective and claims analysts were unaware of the study; hence, both HbAlc and MPR were obtained through blinded personnel.

MPR was calculated as (total days of supply)/(last rx date-first rx date+last rx days of supply); that is, ratio of days medication supplied (numerator) to days in the time interval (denominator). Note that this calculation requires at least two fills during the relevant time interval. The numerator was the sum of days supplied from the first to the last prescription, inclusive. The denominator was the time between the first and last prescription date, plus days supplied of the last prescription. When there was more than one diabetes medication per time interval, the numerator was divided by the number of concurrent medications. Dose changes and switches in medication were not counted as separate medications.

\section{Secondary measures}

The following self-reported assessments were completed at preintervention and postintervention visits and used to assess potential relationships with MPR and HbAlc: Adherence Starts with Knowledge (ASK-20), ${ }^{34}$ Morisky Adherence Scale, ${ }^{37}$ Patient Activation Measure (PAM-13), ${ }^{38}$ Appraisal of Diabetes Scale, ${ }^{39}$ Interpersonal Support Evaluation List (ISEL-12), ${ }^{40}$ Perceived Stress Scale (PSS-4) ${ }^{41}$ Short-Form Health Survey (SF-12), ${ }^{42}$ and Benefit-Finding Scale. ${ }^{43}$ Exercise frequency was measured by asking patients how many times per week they participated in aerobic, stretching, or strengthbuilding activities for at least 20, 15, and 10 minutes respectively per time.

\section{Statistical analysis}

Statistical analyses were performed using SPSS V.22. Univariate analyses were used to compare baseline demographics (independent sample $\mathrm{t}$ tests, $\chi^{2}$, Mann-Whitney U). Repeated measures analyses of variance (ANOVA) with Greenhouse-Geisser corrections were used to detect differences in MPR among the pre, coaching, and post intervals. A paired sample t test was used to examine changes in HbA1c. Pearson correlation was used to measure the relationship between MPR and HbAlc. Wilcoxon signed-rank tests were used for psychosocial surveys with non-parametric distributions.

\section{RESULTS}

\section{Participants}

Table 1 shows the sociodemographic characteristics for all enrolled participants. Mean age was 53.0 \pm 7.93 years; $76.8 \%$ female, $57.1 \%$ African-American; $39.3 \%$ married; $71.4 \%$ lived either alone or with one other person; $55.4 \%$ had annual household income $<\$ 50000 ; 58.9 \%$ had an education level below a college degree. Average length of diabetes diagnosis was $11.2 \pm 7.57$ years.

\section{Recruitment and retention}

Of 114 participants who were recruited, 56 met inclusion criteria, enrolled, and attended the baseline assessment. Eight withdrew over the course of the study for the following reasons: lack of time or interest $(n=6)$, changed health insurance $(n=1)$, and lost to follow-up $(n=1)$. Of the 48 participants who attended both pre and post visits, $45(94 \%)$ attended all 14 coaching sessions.

\section{Inclusion in analyses}

Owing to the requirements for calculating MPR (at least two fills per relevant time period), all available data were used for each of the following analyses: (1) change in MPR, (2) change in HbAlc, and (3) correlation between MPR change and HbAlc change. Of 56 intent-to-treat (ITT) participants, the number who met criteria for MPR calculations (at least two fills per time point, per medication) were $n=50, n=42$, and $n=42$ for pre, coaching, and post, respectively; as a result, 39 participants had all three MPR values for ANOVA procedures. For pre-post HbAlc analyses, 48 participants attended previsit and postvisit for surveys and blood draws; one participant had sickle cell disease precluding use of bloodwork for HbA1c $(n=47)$. Of these 47 participants with available HbA1c data, 36 had MPR values for both pre and coaching intervals, providing data for correlation analysis between MPR change and HbA1c change $(n=36)$.

\section{Primary outcomes (MPR and HbA1c)}

A repeated measures ANOVA with a Greenhouse-Geisser correction determined that mean MPR differed statistically between time points $(\mathrm{F}(1.49,56.54)=7.33, \mathrm{n}=39$, $\mathrm{p}=0.004)$. Post hoc tests revealed that the precoaching MPR of $0.74 \pm 0.197$ was lower than both the intervention MPR of $0.85 \pm 0.155(\mathrm{p}=0.001)$ and the postintervention MPR of $0.82 \pm 0.175(\mathrm{p}=0.011)$. The coaching and 
Figure 1 Medication adherence calculated by pharmacy claims data. IHC, integrative health coaching; MPR, medication possession ratio; n.s., not significant.

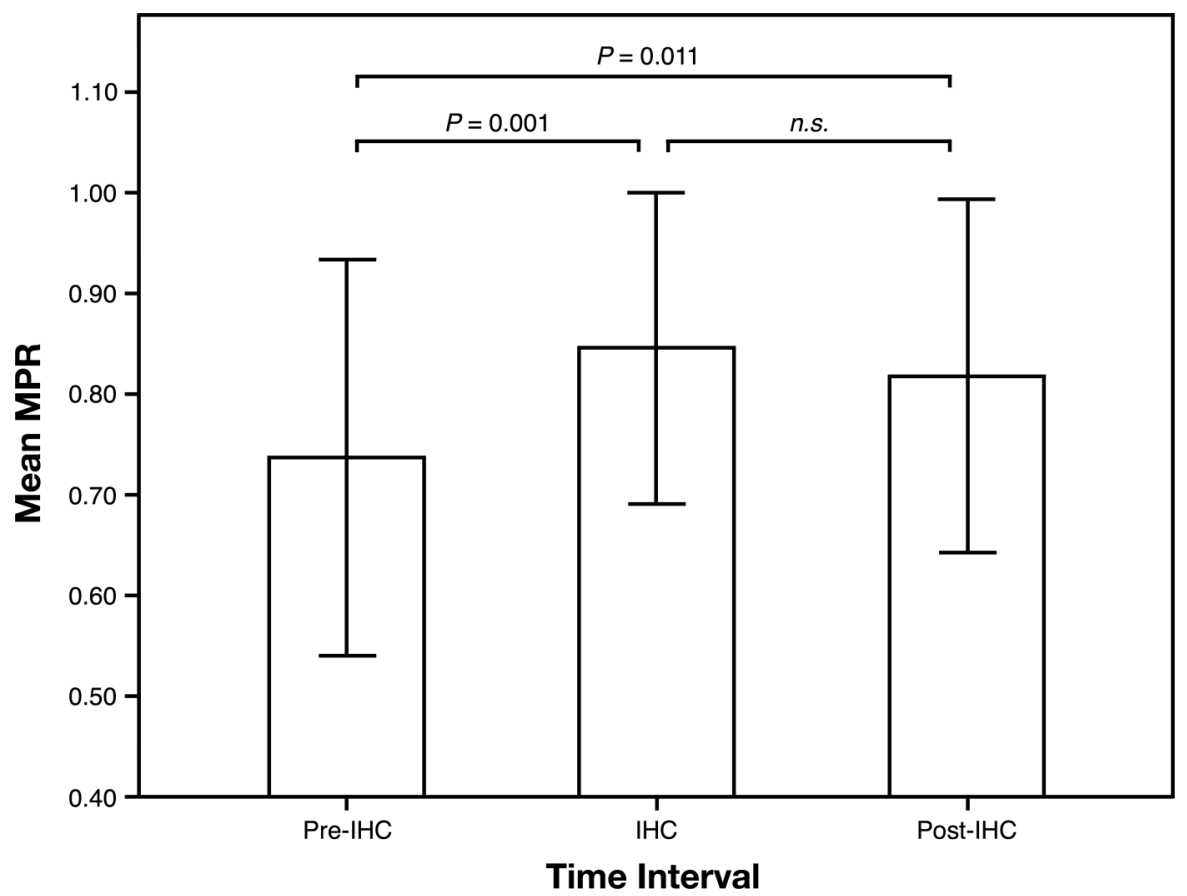

post-MPR were statistically similar $(\mathrm{p}=0.147)$, suggesting adherence improved during the intervention and was sustained afterwards (figure 1).

MPR changes were confirmed by looking at proportion of patients with $\mathrm{MPR}>0.80$. A Friedman test showed a statistical difference at the three time points $\left(\chi^{2}(2)\right.$ $=6.188, \mathrm{n}=39, \mathrm{p}=0.024)$. Post hoc analysis revealed that before the intervention, the proportion of patients with MPR $>0.80(44.0 \%)$ was significantly lower than during coaching $(64.3 \% ; \mathrm{p}=0.009)$ and following coaching

Table 1 Baseline demographics

\begin{tabular}{lll}
\hline & & $\begin{array}{l}\text { Intent-to-treat } \\
(\mathbf{n}=56)\end{array}$ \\
Age (years) & Mean \pm SD & $\mathbf{5 3 . 0 \pm 7 . 9 3}$ \\
\hline Gender, $\mathrm{n}(\%)$ & Male & $13(23)$ \\
& Female & $43(77)$ \\
Race, $\mathrm{n}(\%)$ & White & $22(39)$ \\
& Black & $32(57)$ \\
Marital status, $\mathrm{n}(\%)$ & Asian & $2(4)$ \\
& Single & $11(20)$ \\
Household size, $\mathrm{n}(\%)$ & Married & $24(43)$ \\
& Divorced & $21(38)$ \\
& 1 & $20(36)$ \\
Household income, $\mathrm{n}(\%)$ & 2 & $20(36)$ \\
& $\geq 350000$ & $16(29)$ \\
Education, $\mathrm{n}(\%)$ & $31(55)$ \\
& $<\$ 50000$ & $25(45)$ \\
Diabetes duration (years) & Mean \pm College & $33(59)$ \\
HbA1c & Mean \pm SD & $23(41)$ \\
\hline HbA1c, glycated hemoglobin. & & \\
& &
\end{tabular}

(54.8\%; $\mathrm{p}=0.038)$. There was no change from coaching to the postcoaching interval $(\mathrm{p}=0.276)$, again suggesting that adherence continued after the intervention.

$\mathrm{HbA1c}$ was measured at baseline and immediately after the 6-month intervention. The average HbA1c decreased from $8.0 \pm 1.92 \%$ to $7.7 \pm 1.70 \%$ (64 to $61 \mathrm{mmol}$ / mol; $\mathrm{t}(46)=-1.93, \mathrm{n}=47, \mathrm{p}=0.030)$. The proportion of participants with $\mathrm{HbA} 1 \mathrm{c}<7 \%$ increased significantly, from $25.0 \%$ to $34.4 \%(\mathrm{p}<0.016)$.

The change in MPR was correlated with change in HbAlc, such that better adherence was related to a greater decrease in HbAlc $(r=-0.43, n=36, p=0.004)$.

\section{Psychosocial measures}

Wilcoxon signed-rank tests revealed significant improvements in all survey measures from baseline to follow-up. Perceived barriers to medication adherence decreased (ASK-20: $42.2 \pm 8.14$ to $36.9 \pm 9.10, \mathrm{p}=0.001$ ) and selfreported adherence improved (Morisky: $6.8 \pm 1.10$ to 7.2 $\pm 1.06, \mathrm{p}<0.001)$. Patient activation, defined as having the knowledge, skills, and confidence for self-management, increased (PAM: $65.5 \pm 17.32$ to $77.4 \pm 18.25, \mathrm{p}<0.001$ ). Mood improved (Burns Mood Scale: $11.7 \pm 10.96$ to 9.5 $\pm 10.82, \mathrm{p}=0.010$ ), perceived stress decreased (PSS-4: 5.7 \pm 3.29 to $4.4 \pm 3.05, \mathrm{p}=0.013$ ), and overall morale regarding having diabetes improved (Appraisal of Diabetes Scale: $17.7 \pm 5.09$ to $15.3 \pm 4.56, \mathrm{p}<0.001)$. Participants noted greater social support (ISEL-12: $38.0 \pm 7.84$ to 41.2 $\pm 7.14, \mathrm{p}=0.001$ ) and were able to perceive diabetes as making more positive contributions to their lives (Benefit Finding Scale: $47.1 \pm 21.20$ to 51.2 \pm 20.85 , $\mathrm{p}=0.006)$. Self-reported exercise increased from a median response of ' 0 times per week' to ' $1-2$ times per 
week' $(\mathrm{p}<0.001)$. No correlations were observed between survey scores and MPR, or between surveys and HbAlc.

\section{Coaching topics}

Nutrition and physical activity were discussed at $86.9 \%$ of calls, stress management was discussed during $39.8 \%$ of calls, and social support or relationships were discussed during $15.4 \%$ of calls.

\section{DISCUSSION}

In this longitudinal study of a 6-month telephonic IHC intervention, diabetes medication adherence was objectively measured using pharmacy claims data. MPR calculations revealed an increase in adherence, which persisted for a 6-month period after the intervention. Mean HbAlc decreased during the intervention. Prepost changes for MPR and HbAlc were verified with secondary analyses: proportion of patients with $\mathrm{MPR}>0.80$ increased, and proportion of participants with $\mathrm{HbAlc}<7 \%$ increased. Finally, better adherence was correlated with a greater decrease in HbAlc.

In addition to these primary outcomes, the potential for IHC to facilitate success in multiple areas was evidenced by consistent improvement in all psychosocial assessments. Validated survey instruments showed patients had less perceived stress, better mood, greater perceived social support, improved engagement, and a more positive assessment of their chronic illness. Behavior change was also evidenced by a self-reported increase in exercise frequency. This wide array of improvements may be linked to the fact that patients chose goals and topics that were most important to them, ranging from nutrition and exercise (mentioned during $87 \%$ of conversations), stress management (in $40 \%$ of the calls), and social support and relationships (in $15 \%$ ). It was surprising that our analysis did not detect psychosocial changes correlated with change in adherence.

Because patients discussed whatever issues were most relevant to them, examples of short-term goals included: 'go to the singles potluck this week'; 'use the hot tub to de-stress'; 'schedule a meeting with HR about career counseling'; 'do laundry on two nights rather than every night'; and 'take a walk and call my sister when I get frustrated at work'. While seeming unrelated to medication adherence, such goals empower patients, build confidence, and provide insight into one's own habits. The coach's task was to help the patient discover how changes actually occur, so the patient could use selfdiscovered strategies and apply them to different areas.

It is difficult to compare our findings with those of the literature due to a significant confound in the use of the term: health coach. As of March 2016, Web of Science returned 289 publications for 'diabetes coaching', with over half of them published in the previous 3 years. This surge of studies has come with difficulties comparing results, however, because coaching refers to myriad practices, many of which do not include patientchosen goals, active learning, or self-monitoring of behavior skills. A clear definition of a health coach has only recently emerged as "a healthcare professional trained in behavior change theory, motivational strategies and communication techniques, which are used to assist patients to develop intrinsic motivation and obtain skills to create sustainable change". ${ }^{4}$

Despite the heterogeneous methods used in previous diabetes coaching studies, published results have shown the following trends: (1) simple, straightforward interventions usually do not work; ${ }^{14} 4546$ (2) medication adherence is not sustainable beyond the intervention period $^{47}$ and (3) adherence measured by self-report may be inaccurate. ${ }^{48-50}$

A recent study targeting diabetes medication adherence found that a simple, low-intensity telephonic intervention did not work. ${ }^{46}$ In that study, a diabetes educator or clinical pharmacist delivered one scripted telephone call up to $5 \mathrm{~min}$ duration. Less than half of patients received a successful telephone call, and adherence did not improve. A published comment to that study ${ }^{14}$ described a more intensive intervention of three telephone contacts of 30 min per call. ${ }^{45}$ Their study was also unsuccessful. The authors concluded that "having a trained and dedicated health professional with sufficient time to engage and build rapport with patients, sustained over time, may be critical to supporting patient medication adherence and treatment intensification". We agree that sufficient time and rapport is necessary to promote behavior change, and we further suggest that calls may need to include structured interventions focused on eliciting client's internal motivation and attainment of self-determined goals.

Using a coaching intervention that focused on achieving treatment targets and guidelines, one trial found telephone coaching to be effective during the study, but results were not sustained. ${ }^{47}$ We propose that behavior skills become long lasting when they are integrated and linked to internal motivation. 'Coaching' to external treatment guidelines, like those used in that study, simply may not access the same level of motivation. In IHC, the primary objective involves gaining insight into one's own motivation and behavior, and achieving predetermined targets is a secondary emphasis. IHC is designed to target internal motivation by identifying and focusing on the patient's sense of purpose, not just diabetes-related goals. While longevity of specific behavioral changes remains an empirical question for further study, having patients own the learning process makes intuitive sense, particularly given new Affordable Care Act models that call forth engaged patients. ${ }^{23}$

This study has clear strengths. First, claims data and MPR are often reserved for medication trials or large database analyses but less commonly as outcomes for behavioral trials. Self-reported adherence is much more common in intervention studies; however, self-report is often deemed unreliable in behavioral research trials 
because of recall bias or social desirability bias. ${ }^{48-50}$ Second, this study assessed whether the intervention had lasting effects on behavior, by measuring MPR during a 6-month interval after the intervention ended. Measurement of sustainable change is important in any study that wishes to extrapolate the impact of an intervention after it ends. ${ }^{51} \mathrm{~A}$ third strength involves an intervention that is easily reproducible. Given the success of the IHC approach in helping self-manage chronic conditions, training programmes have been created, and the approach has been described in detail. ${ }^{23-26} 354452$ Finally, we provide evidence that patients become engaged in the coaching process, with 45 of the 48 patients who received coaching (94\%) completing all 14 sessions with their coach.

While the use of pharmacy claims is a strength of the study, the calculation of MPR also has limitations. The formula for MPR requires at least two fills per time period, per medication; hence, participants who do not meet this criterion have very poor adherence. Although we strengthened our study by performing a more conservative analysis of MPR with the ITT sample $(n=56)$, rather than with only those who received coaching $(n=48)$, we were surprised to find that only 39 of the 56 ITT participants $(69.6 \%)$ had data available to calculate MPR for all three time intervals. This likely resulted in inflated adherence estimates for the analyzed group, since those who did not meet the minimum criterion could not be included. On the other hand, our small sample allowed for manual scrutiny of the pharmacy claims data, ensuring that dose changes and medication switches were not counted as separate medications. This likely increased the external validity of our MPR calculations, since medication switches were frequent, and this has been shown to affect the accuracy of automated MPR. ${ }^{53}$

Furthermore, the limits of MPR as a proxy for medication adherence are worth noting. Patients obtaining medications from the pharmacy does not ensure that medications are taken as prescribed. MPR does not assess if patients are inappropriately using, sharing, hoarding, or discarding medications. This further underscores the need for effective behavioral interventions and also highlights the need for innovative measurement technologies to study medication non-adherence.

In conclusion, IHC supports oral medication adherence for patients with diabetes during coaching, and afterwards. Helping patients gain insight into their personal behavior using self-determined goals may uncover internal motivation and link it to behavior skills necessary to increase medication adherence. Personalized treatment strategies are necessary, and further studies should assess which aspects of coaching are particularly helpful for which individual patients.

Acknowledgements The authors gratefully acknowledge Tim Niecko (Niecko Health Economics, LCC) for guidance with pharmacy claims analysis; GlaxoSmithKline for research materials and funding support; Andrew Fenster for assistance with data management; and Jessica Wakefield and Linda Duda, who were the coaches for the study.

Contributors RQW and MHD shared first author responsibilities. RQW designed the parent study and supervised data collection and analysis. MHD conducted data analysis. Both contributed to data interpretation and manuscript writing.

Funding The study was funded by GlaxoSmithKline; however, academic freedom was ensured contractually.

Competing interests None declared.

Ethics approval Duke University Institutional Review Board.

Provenance and peer review Not commissioned; externally peer reviewed.

Data sharing statement No additional data are available.

Open Access This is an Open Access article distributed in accordance with the Creative Commons Attribution Non Commercial (CC BY-NC 4.0) license, which permits others to distribute, remix, adapt, build upon this work noncommercially, and license their derivative works on different terms, provided the original work is properly cited and the use is non-commercial. See: http:// creativecommons.org/licenses/by-nc/4.0/

\section{REFERENCES}

1. Cramer JA. A systematic review of adherence with medications for diabetes. Diabetes Care 2004;27:1218-24.

2. Asche C, LaFleur J, Conner C. A review of diabetes treatment adherence and the association with clinical and economic outcomes. Clin Ther 2011;33:74-109.

3. Shenolikar RA, Balkrishnan R. Oral antidiabetes medication adherence and health care utilization among Medicaid-enrolled type 2 diabetic patients beginning monotherapy. Diabetes Care 2008;31:e5.

4. Balkrishnan R, Rajagopalan R, Camacho FT, et al. Predictors of medication adherence and associated health care costs in an older population with type 2 diabetes mellitus: a longitudinal cohort study. Clin Ther 2003;25:2958-71.

5. Ho PM, Rumsfeld JS, Masoudi FA, et al. Effect of medication nonadherence on hospitalization and mortality among patients with diabetes mellitus. Arch Intern Med 2006;166:1836-41.

6. Wong ES, Bryson CL, Hebert PL, et al. Estimating the impact of oral diabetes medication adherence on medical costs in VA. Ann Pharmacother 2014;48:978-85.

7. Roebuck MC, Liberman JN, Gemmill-Toyama M, et al. Medication adherence leads to lower health care use and costs despite increased drug spending. Health affairs 2011;30:91-9.

8. Beaucage K, Lachance-Demers H, Ngo TT, et al. Telephone follow-up of patients receiving antibiotic prescriptions from community pharmacies. Am J Health Syst Pharm 2006:63:557-63.

9. Derose SF, Green K, Marrett E, et al. Automated outreach to increase primary adherence to cholesterol-lowering medications. JAMA Intern Med 2013;173:38-43.

10. Vollmer WM, Feldstein A, Smith DH, et al. Use of health information technology to improve medication adherence. Am J Manag Care 2011;17(12 Spec No.):SP79-87.

11. Viswanathan $M$, Golin $C E$, Jones $C D$, et al. Interventions to improve adherence to self-administered medications for chronic diseases in the United States: a systematic review. Ann Intern Med 2012;157:785-95.

12. Haynes RB, Ackloo E, Sahota N, et al. Interventions for enhancing medication adherence. Cochrane Database Syst Rev 2008;(2): CD000011.

13. Nieuwlaat R, Wilczynski N, Navarro T, et al. Interventions for enhancing medication adherence. Cochrane Database Syst Rev 2014;11:CD000011.

14. Blackberry ID, Furler JS, Best JD, et al. Comment on O'Connor et al. Randomized trial of telephone outreach to improve medication adherence and metabolic control in adults with diabetes. Diabetes Care 2015;38:e45.

15. Williams JLS, Walker RJ, Smalls BL, et al. Effective interventions to improve medication adherence in type 2 diabetes: a systematic review. Diabetes Management 2014;4:29-48.

16. Mayberry LS, Osborn CY. Empirical validation of the information-motivation-behavioral skills model of diabetes medication adherence: a framework for intervention. Diabetes Care 2014:37:1246-53. 
17. Heisler M, Piette JD, Spencer M, et al. The relationship between knowledge of recent $\mathrm{HbA1c}$ values and diabetes care understanding and self-management. Diabetes Care 2005;28:816-22.

18. Coates VE, Boore JR. The influence of psychological factors on the self-management of insulin-dependent diabetes mellitus. J Adv Nurs 1998;27:528-37.

19. Schoenthaler AM, Schwartz BS, Wood C, et al. Patient and physician factors associated with adherence to diabetes medications. Diabetes Educ 2012;38:397-408.

20. Morello CM, Chynoweth M, Kim H, et al. Strategies to improve medication adherence reported by diabetes patients and caregivers: results of a taking control of your diabetes survey. Ann Pharmacother 2011:45:145-53.

21. Lorig K, Laurent DD, Plant $\mathrm{K}$, et al. The components of action planning and their associations with behavior and health outcomes. Chronic IIIn 2014;10:50-9.

22. Simmons LA, Wolever RQ, Bechard EM, et al. Patient engagement as a risk factor in personalized health care: a systematic review of the literature on chronic disease. Genome Med 2014;6:16.

23. Smith LL, Lake NH, Simmons LA, et al. Integrative health coach training: a model for shifting the paradigm toward patient-centricity and meeting new National Prevention Goals. Glob Adv Health Med 2013;2:66-74.

24. Wolever RQ, Caldwell KL, Wakefield JP, et al. Integrative health coaching: an organizational case study. Explore (NY) 2011;7:30-6.

25. Wolever RQ, Eisenberg DM. What is health coaching anyway? Standards needed to enable rigorous research. Arch Intern Med 2011;171:2017-18.

26. Caldwell KL, Gray J, Wolever RQ. The process of patient empowerment in integrative health coaching: How does it happen? Glob Adv Health Med 2013;2:48-57.

27. Edelman D, Oddone EZ, Liebowitz RS, et al. A multidimensional integrative medicine intervention to improve cardiovascular risk. $J$ Gen Intern Med 2006;21:728-34.

28. Wolever RQ, Webber DM, Meunier JP, et al. Modifiable disease risk, readiness to change, and psychosocial functioning improve with integrative medicine immersion model. Altern Ther Health Med 2011;17:38-47.

29. Fikkan JL, Baime M, Sanders L, Greeson J, Jennifer W, Wakefield J, et al. Mindfulness in the maintenance of weight loss: a randomized controlled trial of the EMPOWER program. Paper presented at the 11th International Congress of Behavioral Medicine, Washington, D.C. [Abstract published in International Journal of Behavioral Medicine, 2010, 17 (Suppl 1): OS19-E.]

30. Caldwell K, Baime M, Wolever R. Mindfulness based approaches to obesity and weight loss maintenance. J Mental Health Couns 2012;34:269-82.

31. Wolever RQ, Caldwell K, Fikkan J, Greeson J, Sanders L, Webb J, et al. Enhancing mindfulness for the prevention of weight regain: impact of the EMPOWER program. Paper presented at the 33rd Annual Meeting \& Scientific Sessions of the Society of Behavioral Medicine, New Orleans, LA. [Abstract published in Annals of Behavioral Medicine, 2012, 43 (Suppl 1).].

32. Kosey J, Wolever R. 22B. Integrative therapy for patients with severe tinnitus. Glob Adv Health Med 2013;2:22B.

33. Wolever RQ, Dreusicke M, Fikkan J, et al. Integrative health coaching for patients with type 2 diabetes: a randomized clinical trial. Diabetes Educ 2010;36:629-39.

34. Matza LS, Yu-Isenberg KS, Coyne KS, et al. Further testing of the reliability and validity of the ASK-20 adherence barrier questionnaire in a medical center outpatient population. Curr Med Res Opin 2008;24:3197-206

35. Simmons LA, Wolever RQ. Integrative health coaching and motivational interviewing: synergistic approaches to behavior change in healthcare. Glob Adv Health Med 2013;2:28-35.

36. Jordan $\mathrm{M}$, Wolever $\mathrm{RQ}$, Lawson $\mathrm{K}$, et al. National training and education standards for health and wellness coaching: the path to national certification. Glob Adv Health Med 2015;4:46-56.

37. Morisky DE, Green LW, Levine DM. Concurrent and predictive validity of a self-reported measure of medication adherence. Med Care 1986;24:67-74.

38. Hibbard JH, Mahoney ER, Stockard J, et al. Development and testing of a short form of the patient activation measure. Health Serv Res 2005;40Pt 1):1918-30.

39. Carey MP, Jorgensen RS, Weinstock RS, et al. Reliability and validity of the appraisal of diabetes scale. J Behav Med 1991;14:43-51.

40. Cohen S, Mermelstein R, Kamarck T, et al. Measuring the functional components of social support. Soc Support Theory Res Appl Springer 1985:73-94.

41. Cohen S, Kamarck T, Mermelstein R. A global measure of perceived stress. J Health Soc Behav 1983;24:385-96.

42. Ware J Jr, Kosinski M, Keller SD. A 12-Item Short-Form Health Survey: construction of scales and preliminary tests of reliability and validity. Med Care 1996;34:220-33.

43. Tomich PL, Helgeson VS. Is finding something good in the bad always good? Benefit finding among women with breast cancer. Health Psychol 2004;23:16-23.

44. Wolever RQ, Simmons LA, Sforzo GA, et al. A systematic review of the literature on health and wellness coaching: defining a key behavioral intervention in healthcare. Glob Adv Health Med 2013;2:38-57.

45. Blackberry ID, Furler JS, Best JD, et al. Effectiveness of general practice based, practice nurse led telephone coaching on glycaemic control of type 2 diabetes: the Patient Engagement And Coaching for Health $(\mathrm{PEACH})$ pragmatic cluster randomised controlled trial. $B M J$ 2013;347:f5272.

46. O'Connor PJ, Schmittdiel JA, Pathak RD, et al. Randomized trial of telephone outreach to improve medication adherence and metabolic control in adults with diabetes. Diabetes Care 2014;37:3317-24.

47. Varney JE, Weiland TJ, Inder WJ, et al. Effect of hospital-based telephone coaching on glycaemic control and adherence to management guidelines in type 2 diabetes, a randomised controlled trial. Intern Med J 2014;44:890-7.

48. Van de Mortel TF. Faking it: social desirability response bias in self-report research. Australian Journal of Advanced Nursing 2008;25:40-8

49. Podsakoff PM, MacKenzie SB, Lee JY, et al. Common method biases in behavioral research: a critical review of the literature and recommended remedies. J Appl Psychol 2003;88:879.

50. Fisher R, Katz JE. Social-desirability bias and the validity of self-reported values. Fisher, Robert J and James E Katz, (2000) "Social Desirability Bias and the Validity of Self-Reported Values." Psychol Mark 2008;17:105-20.

51. Craig P, Dieppe $\mathrm{P}, \mathrm{Macintyre} \mathrm{S}$, et al. Developing and evaluating complex interventions: the new Medical Research Council guidance. BMJ 2008;337:a1655.

52. Wolever RQ. Collaboration and synergy in the field of health and wellness coaching: naive or necessary? Glob Adv Health Med 2013;2:8-9.

53. Martin BC, Wiley-Exley EK, Richards $\mathrm{S}$, et al. Contrasting measures of adherence with simple drug use, medication switching, and therapeutic duplication. Ann Pharmacother 2009;43:36-44. 